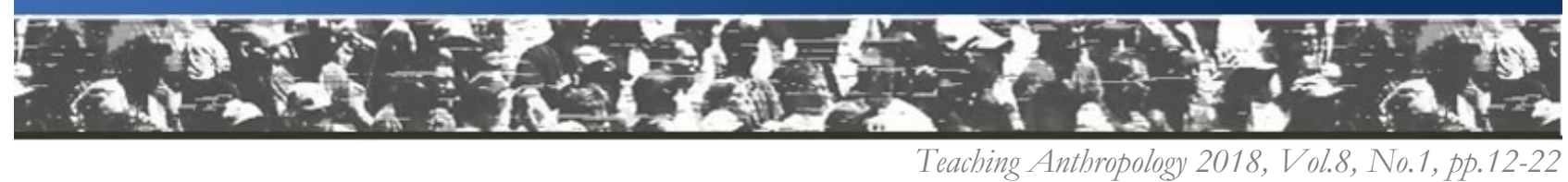

\title{
Transformative Ethnography: teaching the art of fieldwork
}

\author{
Lisa Feder \\ Academy of Art University
}

\begin{abstract}
Transformative ethnography is a method of learning to cross cultures through an embodied, experiential, and reflective practice. I have developed this method over fifteen years of anthropological fieldwork and reflection. This methodology requires the practitioner to embody a foreign practice, generally through art, music, or a specialized skill or technique. She moves through four phases that overlap and intertwine as she goes about the ethnographic process: sensorial observation, embodying practice, emptying and reflecting, and embodying representation. The purpose of Transformative Ethnography is to become explicitly aware of the process of loosening ones own, and adopting to another cultural way of thinking and acting. The overarching research question to this methodology asks How can we re-make ourselves, consciously, in order to fit new (multi-) cultural realities? It is controversial in that it incorporates mindfulness training - something not yet broadly accepted in our discipline. It is creative in that it draws on art-based techniques of observation and embodiment in ways that select few anthropologists are using in the field today.
\end{abstract}

\section{Introduction}

Transformative Ethnography is a method of learning to cross cultures through an embodied, experiential, and reflective practice, meant for anthropology students or any students practicing to be cross-culturally literate. I developed this method over fifteen years of anthropological fieldwork and reflection in the Kayapo indigenous area in Brazil, and with the Manding community in West Africa and New York. This methodology requires the practitioner to embody a foreign practice, generally through art, music, or a specialized skill or technique. She moves through four phases that overlap and intertwine as she goes about the ethnographic process:

- Sensorial Observation

- Embodying Practice

- Emptying and Reflection,

- Embodying Representation.

In the first stage the practitioner becomes oriented through observation before attempting execution, and gradually increases to intensive practice until she becomes more proficient. She includes lengthier times for 'emptying' -or not engaging in mental and physical stimulation—and reflecting on her position in the culture and her progress in the learning process. Following this methodology enables her to eventually embody, express, and perform within the native context. A significant aspect of that is opening herself up to critique on her successes and failures by her native teachers. In this method the practitioner is learning to express herself according to a new sensibility. Moreover, she becomes aware of her own culturally-ingrained patterns as she reflects on her own progress. As a result, not only does she learn a new sensibility, she learns how to learn in a new way.

Envisioning ourselves as teachers of Transformative Ethnography (TE), we would already have significant crosscultural participatory fieldwork, whether that fieldwork is in some far away culture, or another aspect of one's own culture. ${ }^{1}$ TE could be taught and practiced as a methods-component to an anthropology class with exercises among the students in the classroom itself, or conceived through mini-field projects. Optimally, I envision it as an approach to studying abroad, perhaps a cultural immersion class with a fieldwork component, or an entire field school dedicated to intensive, participatory, cross-cultural learning.

The guiding questions that drive the practice of Transformative Ethnography are:

1 For example, a large part of my fieldwork takes place in my home city in which there is a sizable population of West African immigrants. I shift between two cultural realities every day. One could even shift between sub-cultural realities in a given location: academic vs. corporate. Academic vs. agricultural. European-American vs. Asian-American, Christian vs. Jewish or Muslim, Athlete vs. artist, etc... 
- What makes the cultural being?

- How can we re-make ourselves, consciously, in order to fit new (multi-) cultural realities?

As anthropologists, we become increasingly aware that we are culturally enmeshed. We reenact babitus (Bourdieu 1990) mostly unconsciously, in order to meet our needs and express ourselves within our society. Patterns in culture, as foundational thinkers in the field have argued, are made of information tidbits that repeat and change slowly like nature's evolution (Bateson 1972). These patterns are culturally specific, focused on the 'moral imperatives' within that cultural reality that orient individuals' behaviors (Benedict 1934). When we train in changing our patterns to another cultural modality, we begin to sense these moral imperatives that may exist on a sub-conscious level. We might resist change, as our own habitus surfaces and bumps up against new cultural patterning. The transformation occurs when we can overcome the resistance and shift between two cultural modalities.

\section{Creativity and Controversy}

The purpose of Transformative Ethnography is to become explicitly aware of the process of loosening ones own, and adopting to another cultural way of thinking and acting. It is a particular kind of participant observation in that it unabashedly encourages attempts to "go native" within a particular segment of culture, and it explores through self- and group-reflection, the emotional and psychological, as well as intellectual transformations that occur, as we cross cultures. Furthermore, it creates a place for these revelations in ethnographic representation in the form of text and other creative expression.

Few ethnographic field schools teach field methods such as note-taking, participant-observation, and interviewing Select few anthropologists discuss body training in their ethnographies explicitly (see Csordas 1990, Downey 2010, Pink 2015, Stoller 1987). But by and large, in anthropology and other social sciences we do not train students in mind- and body-training in preparation for doing fieldwork. In this article, I am proposing a disruption in our current epistemological ways of speaking about and teaching fieldwork in anthropology, and inserting a conscientious effort to teach awareness and transformation of the mind and body in the art of crossing cultures. This style of cross-cultural learning reverses the traditional power hierarchy of researcher-toinformant by placing the researcher in the logical position of student, or apprentice, in the host culture, the neophyte body as a vessel that needs to be emptied and re-programmed in how to move, act, and think.

It should be noted that this methodology intersects with a fringe and disparate group of anthropologists that experiment with creative and artistic methodologies in their own work and have dared to write about it. Some of their methods include improvisational and other theater techniques (Dumit 2017, and Jain 2015) as well as creative writing, photography, film, sound, performance and exhibition, (see Elliot and Culhane 2017, CastingTaylor 2017), bodily communication through touch (Myers and Dumit 2011), and the intersection of art and anthropology (Schneider and Wright 2013). Their inquiry into artistic methods for anthropology has identified the researcher's body and mind appropriately as sensorial, reflective, culturally-enmeshed, and subjective in the process of fieldwork. Nevertheless, there are few who address explicitly the process of what I call, transformation, how the researcher's body transforms into another cultural mode of being, as the central question of research (see Stoller and Olkes 1987, Downey 2010). Transformative Ethnography may be controversial in stating upfront that we can methodologically study the process of shifting our subjective bodies to suit another cultural orientation, and train our students to do the same. Taking a closer look at these four phases may shed light on their value and how they work to do this.

\section{The Four Phases to Transformative Ethnography}

- Sensorial Observation as cultivating a disciplined focus of sensorial patterns in the host culture. Participants embark on mini-field observations while honing in on particular senses such as smells, colors, sounds, or rhythms, in select locations in the host culture, and experiment with recording their experiences through various media.

- Embodying Practice as practicing an art, aesthetic, style, skill, trade, or craft. Through an independent study, which may include apprenticeship, participants sync up with and embody one aspect of the culture, cultivating a mindful attention to their experience.

- Emptying and Reflecting Emptying is time prior to fieldwork activity for calming the mind, bringing attention to the present, to focus on bodily sensations, calming thoughts, observing emotions. This preps the mind/body for mindful attention to participation in the field. Reflecting is quiet time to process field experiences, including one's own learning process, through meditation, journal-writing, and class discussion. We develop skills in reflexivity. 
- Embodying Representation is representing or performing the independent study with possible assistance of creative media. Participants express culture to others through an embodying performance, one in which both the ethnographer and the audience may have a sensorial experience of the culture.

\section{Situating Transformative Ethnography: expressive, sensorial, reflective practices}

Though Transformative Ethnography is a new approach, it is deeply informed by several established anthropological theories that intertwine. ${ }^{2}$ The ethnography is transformative for the researchers because they learn to express themselves through a foreign repertoire of possibilities. They are learning new habitus by emplacing themselves in a logical social position in the society. For one, practitioners become students, an appropriate place to start fieldwork. Secondly, one chooses a skill or art that has a determined social position within that society, one that has specific patterns that mark the person's social standing (Bourdieu 1990). TE is an application of Hans Joas' theory for an expressive anthropology as well. Joas says, "our perception of the world appears to be structured by our capacities for, and experience of, action" (1996:158). People know themselves in the act of expressing and in how others receive their expressions, which are continually fine-tuned in action. This methodology also practices Goffman's face-to-face interactions (1967) and Hall's proxemics (1966), and experiences of time (1983). This kind of practice emphasizes tacit knowledge, less accessible from a more cognitive, analytical type of ethnography. Donald Schön explains that "knowing is in the action" in which "tacit knowledge" acquired through experience comes out in the doing before one can even speak about it, if at all (1987).

The sensorial anthropologists shift the position of the anthropologist in the field to a subjective, feeling, sensing participant marked by her own cultural babitus. She is 'emplaced' in a fieldsite (Pink 2015: 30), in which she shares in a collaborative construction of meaning based not only on conversations but a whole sensorial experience that include movements, rhythms, colors, smells, tastes, and more, each sense of which makes up 'different facets of the same activity" (Ingold 2000: 261). It builds on Merleau-Ponty's phenomenology and Bourdieu's theory of practice (see Csordas 1990 and Downey 2010), explores sensorial hierarchies (Howe 2003, Howes and Classen 2014) and explores how the researchers body and mind change throughout the learning process as cultural immersion increases.

Ideas are shared among a fringe group of anthropologists (see Pink 2015, Dumit and Myers 2011, Elliot and Culhane 2017), but how do we teach these methods to our students? The remainder of this article draws on my own work and that of like-minded anthropologists to further develop innovative field techniques using the arts and contemplative practices. I draw on examples from my own fieldwork with Manding jalis, my pilot fieldschool program in Belgrade (2015) developed with Dr. Marko Zivkovic of University of Alberta, and other anthropologists' recent examples both from the classroom and in the field. Transformative Ethnography is a malleable, flexible approach with specific guiding questions and a structure with four phases and sub-phases, of which are described in detail, below.

\section{Doing Transformative Ethnography}

TE was conceived from a feeling that, in the anthropology classroom and the study abroad industry, there is a lack of vigor in guiding students into having meaningful cross-cultural experiences. In anthropology, our ethnographic writing does represent some of the most interesting experiences in the field that include our own "vulnerable observations" (Behar 1997) or participations, to say the least of teaching real methods in navigating such experiences. My fieldwork consists of musicking (Small 1998)—participating in live musical scenes—with Manding West Africans, as a passionate hobby and a site for anthropological research. I've struggled in academic writing with how to convey the embodied and heart-felt experiences that I have shared with people in the field, experiences that for me, reveal the essence in importance of what it is to cross cultural borders. Furthermore, I've been studying, volunteering and then working in study abroad industry intermittently since high school with Putney Student Travel, World Teach, Syracuse DIPA programs, S.I.T., and elsewhere. These programs tend to specialize in immersing students, but on many standard college and university programs abroad, students have little to no guidance in cross-cultural immersion, nor critical analysis about their experiences. I see a missing

2 TE also aligns well with Jack Mezirow's Transformational Learning Theory for adult learners in which 'disorienting dilemmas' are opportune for expanding or transforming meaning structures, and adults learn by sharing experiences with the group (see Mezirow 1991). 
opportunity; thus, my proposal for TE which, through classroom and field exercises, whether at home or abroad, can lead students into have deeper, more critically analyzed, cross-cultural experience. Below, I describe the methodology as I imagine it now, using examples from my fieldwork, my study abroad experiences, other anthropologists' fieldwork who have used similar methods, and from the pilot program I co-designed and ran in Belgrade 2015 that tested some of these ideas with willing and enthusiastic students from University of Alberta.

\section{In the classroom}

Consider the Transformative Ethnography classroom as a lab for creative trials, a place for preparation, and a space for decompressing/debriefing/reflecting. The students are researchers on a mission, together, to discover what makes them cultural beings, how they can transform their conditioned ways of using the mind and body to a foreign modality, and how this affects or transforms them emotionally and psychologically. We may use creative and other writing techniques, visual arts, performance, improvisation, dance, and more to prepare for and process field experiences. In the classroom we explore individual versus group responses to a foreign stimulus. We explore concepts such as culture, context, reflexivity, ethnocentrism - by creating these experiences as a group. We consider culture seen through, race, religion, social status, gender, and how we are molded, and segregated, through our senses, emotions, intellect, in mind and body, into cultural beings.

The first few classroom sessions are dedicated to getting a baseline reading of what we think we know about ourselves and about the ostensible other. During and after fieldwork, we revisit these ideas and see how they change. There are innumerable exercises that teachers can create and co-generate with other teachers and their students around these topics. I offer two examples, below.

For an exercise on proxemics and propriety: In our Belgrade school, we broke students into two groups. One half was told to wait outside while the others were instructed to change their normal way of interacting: Speak really slow. Stand really close. Light up a cigarette in the classroom. Laugh at everything. When the other half returned, students engaged in casual conversations, using unexpected behaviors. How did this affect the unassuming conversation partner? Later we reflected as a group on how it felt to alter the course of expected behaviors. How did meaning change? What anxieties or other feelings surfaced? For an exercises on ethnocentrism: Have the class come up together with an extensive list of how they have experienced, or they have projected onto another ethnocentric (or other prejudiced) views. Make a long list on the blackboard. Then, have each person write anonymously, one view that they might hold from the list, and might transform through having experiences, asking questions, or otherwise stepping into the shoes of the other. Classes meet regularly throughout the duration of the fieldwork for contemplation, critical discussion, reflection, and creative expression of experiences. The last weeks, or a weekend retreat, is dedicated to an analysis of how students' ideas have developed over the course of the fieldwork.

\section{In the field: Sensorial Observation}

Observational exercises wake up the senses and orient a newcomer to the culture. I like to start with a short meditation before stepping into the world, to calm one's thoughts and prepare for letting new sensorial experiences come in. Then, the neophyte practitioner uses the body-as-tool as a honing, sensing, perceiver/receptor of sensorial patterns while walking through or sitting in specific public locations such as the market, the café, the central square, or various neighborhoods. She or he makes sensorial observations of the outside environment, and notices how external stimuli induce feelings, thoughts, and other reactions in the inner world of the observer (see Pink 2008; Lund 2006, Hissa and Norgueira 2013). The embodied perception is continually interrupted by little reflections - this is different, that is familiar, it feels this way, I like this, I don't like that.

During the first week of the School for Ethnographic Sensibility in Belgrade, students in groups of four or five embarked on sensorial-honing missions. One group observed the colors in the open-air market while another explored the sounds. One day the exercise was to notice the smells while walking to school. Another day students experimented with pace, rhythm, space, and engendered body motions of those walking down the main drag, Knez Mihajlova. Many initial exercises involved walking through the city and sitting in public spaces. Craig Farkash, a participant, commented that "Being taught to bring the senses that I would normally background to the forefront illuminated so much more about the city than I would have otherwise uncovered. We may have viewed a single note at a time, but they eventually all combined to form a symphonic picture of place". In the classroom, they represented their experiences through art, skits, and multi-media. These kind of exercises can get quite specific, and may continue for several weeks as students develop skills and get adjusted to the field. In the classroom, students reflect and present experiences in creative ways. 


\section{Emptying and Reflecting}

Like a ritual, a learning session must be prepared for in advance as well as properly ended before the next activity begins. Prior to a field session, I like to guide practitioners in 'emptying': relaxing and clearing the mind of other thoughts. This prepares the mind and body for filling up with new information from the foreign milieu. Once students become more independent in research, they can choose to incorporate 'emptying' as they wish.

Reflection-on-action (Shön 1987: 83) takes place after the learning session is completed. Practitioners may rest and reflect at length, and they may reflect as a group in the classroom. This is time to contemplate, meditate, write, draw, move, review notes and recordings made during practice. It is also a time to relax and meditate in my classroom, space for the mind and body to sub-consciously assimilation what was experienced. Post-meditation, students are encouraged to journal on experiences of the physical body, sensations, emotions, attitude, state of mind, nature of thoughts. We might ask, what patterns in your own thinking occur? What 'normal' patterns and expectations are interrupted when you are in the field? For a simple example, at breakfast you are used to cereal or eggs. Here they serve cold cut meats and cheeses. We might ask, what is the purpose, meaning, historical context, and added advantage to living this way? Could you imagine incorporating this pattern into your life back home? This is also time to reflect on how we affect our hosts. Do we feel that economic or educational or cultural differences affect the nature of our relationships? Does human, heart-felt connection penetrate through boundaries? What is the nature of the emotional and intellectual connection between you and your hosts (Behar 1997)? We also engaged in remembering through creative writing, drawing, reviewing photos and sound recordings, letting the most salient moments of their experiences come to surface. This marks a rupture from what we may expect happens during fieldwork, and these exercises invite self-reflection into the fieldwork process, itself. In Belgrade, we led students in thirty-minute relaxation meditations. Strewn across the classroom floor, they lied on their backs with palms facing up while I spoke softly of relaxing the body to them. Craig Farkash commented that this time could be the most "beneficial part of one's day. By taking time to meditate on a days work, in as simple or complex a manner as I felt comfortable with, and clearing the mind it allowed me to attack things afresh" (Farkash 2015). Others mentioned how prior to meditation, their bodies were pulsing with energy, over-stimulated, speedy, and some were uncomfortable. This time allowed them to regulate, physiologically and mentally.

\section{Emplacement}

Emplacement refers to placing oneself in a position in the culture that makes sense to the locals, and that enables the research-practitioner to participate. This could mean something as simple as "commonplace activities such as eating and walking" (Pink 2015: 107), following peoples' 'routes and mobilities' (Lee and Ingold 2006), sitting in the public square (Low 2016), or riding public transportation (Lemon 2000). Ideally, emplacement involves studying a practice such as learning to bake a baguette with a local boulanger in Paris, learning the art of capoeira (Downey 2005), of cattle breeding (Grasseni 2004), of Songhay Sorcery (Stoller and Olkes 1987), of Japanese dance (Hahn 2007), Thai music (Wong 2008), or jali music in New York (Feder 2007).

Students choose emplacement based on who they meet, what attracts them, prior experiences and skills. In Belgrade, we were flexible to give students freedom to explore. Some of our students in Belgrade found emplacement quite quickly: a host family sibling musician worked with one of our students. Another student was attracted to the Kafanas, local pub-like restaurants. One woman learned to cook with a "grandma." Another student went on a series of dates, seeking to understand what Belgradian college students are seeking in romance and love. One student wanted to study aggression and anger in public.

\section{Embodying Practice through mimesis}

How do we embody the other? In skilled practices and arts, it is rather logical to act like others in order to achieve the right results. In my research, I used observation and mimesis to integrate into West African jali musical contexts. I honed in on both auditory and bodily sensations, on visual cues, the tap of a musician's foot, the dancing feet of a Manding participant, or my balafon teacher banging out a repeating cycle of notes for me to repeat. I tried to move in time and to capture the spirit of the moves, sometimes looking rather ridiculous. In speaking about his experience in learning Brazilian capoeira, Greg Downey explains, "Bodily learning brings to conscious light some of the movement traits, postures, and tendencies that may have once been unconscious, but become problematized in transformative apprenticeship. As the novice seeks to imitate new styles of moving, one of the central obstacles he or she must confront is unconscious patterning, unexamined inhibition, and corporeal reservations that are only apparent when challenged by new kinaesthetics" (Downey 2010: 27). Reflection-in-action is a natural part of the sensorial, embodying practice phase in which the practitioner makes small adjustments to align with the host sensibility. (Shön 1987: 83, Csordas 1990:36, Joas 1996). The intention is 
to make the learning process a mindful practice in which any thoughts toward a meta-analysis of the practice are merely noted and saved for later reflection.

In Belgrade, Laura, teemed up with her host sister, Sara. They made a video, each one taking a turn to sit in a chair and talk about daily things: their favorite pair of shoes, how they feel about their bed, boyfriends. Then, Laura took Sara's video, memorized her words and body language, and Sara learned Laura's words and body language. They made a new video, Sara lip-syncing Laura's words and using Laura's body language, and viceversa. The final product: One sees Laura on screen acting rather unlike herself, speaking about her life that isn't her life, with a Belgradian accent in English. We realize we are actually hearing Sara's voice, but seeing Lauracum-Sara in the chair. More interestingly, these two did not get along well, and doing this project helped them to see the world from the other's perspective.

\section{Freaking out}

In TE we train practitioners to become familiar with moments of anxiety and to try to appreciate them; they are the precise moment of cross-cultural learning. Anyone who has ever tried to learn djembe drumming with an African teacher may attest to the 'freak outs' that can occur. The teacher will throw a fast pattern at you with no verbal explanation, and expect you to repeat it. Dumbfounded, you struggle to repeat, and fail. The teacher repeats. You try. Repeat. Try. The whole time you are under stress. However, once one becomes accustomed to this style of learning and can calm the mind when 'freaking out', which in turn diminishes, and learning becomes easier.

In the first rendition of my fieldschool in Belgrade 2015, we taught students to "freak out" intentionally. In other words, when patterns of culture did not meet their expectations, we train them to notice, pause, and become conscious of what is jolting, surprising, unexpected. We also train students to reflect on these moments purposefully, to journal about them, to highlight them with the aim to notice differences between patterns of communication between home and host cultures. In the classroom we explore what we expect to happen and what actually happened, and how does this affect us emotionally, psychologically? How can we adjust to these difficult emotions? These moments contain remarkable insights into the greater question of how the cultural being is made. Pink explains, "such disorienting moments are unexpected and they somehow 'jolt' us into a new level of understanding" which may be enjoyable or upsetting (Pink 2015:52). Similarly, Thomas McIlWraith highlights 'disorienting dilemmas' as a particular condition for learning in his fieldschool (McIlwraith 2016: 60), congruent with Mezirow's Transformational Learning Theory (1991).

\section{The benefits of a teacher}

In TE ideally, students links up with local mentors or teachers perhaps a host culture's anthropology student, or a formal teacher of an art or skill. A local teacher or mentor helps sculpt the student's mind and body to the new cultural expression and to catch the student who naturally falls into her own babitus. Hahn explains that one must have a teacher to train the body to conform to set patterns or shapes in order to develop or cultivate the character of the culture (2007: 43). The teacher may expose different ways of perceiving, sensing, and approaching the learning process that provides valuable lessons for understanding deeper values with in the cultural system. The following excerpt from my own fieldwork learning Manding Balafon illustrates the indispensible role of a teacher:

\footnotetext{
The Balafon Workshops

We have learned two long patterns, A and B to the song, Soli. Today, Abou strikes three notes on the balafon and expects us to imitate, then repeat. Simple, I think. Then he strikes three new notes and expects us to imitate and repeat. Then he puts them together. We get this. Next, Abou wants us to play pattern A into pattern B and we are supposed to realize that what we have been practicing is the transition between the parts. We are clumsy and out of time and utterly confused. Don't freak out. Repeat. Repeat. Repeat.

I imitate Abou while longing for a verbal explanation. None comes. I feel that a verbal explanation would avoid the confusion, but Abou insists that we follow him. I resist mentally, but am urged to copy without knowing the reason why. When I drop my resistance to just copying without verbal explanation, my learning progresses. (Feder Ph.D dissertation 2007)
}

Trusting and letting go of habitual patterns of thinking comes about by putting oneself at the mercy of a teacher. It is a matter of trusting another way of approaching a challenge. How Abou teaches us reveals subtle indications about Manding thinking, which exhibits the priority of action and repetition over verbal explanation. In a different context, Abou and I have a conversation about a cultural difference between Americans and Guineans. Abou is 
baffled that 'white people' always ask how will an event be before we experience it. Abou answers 'You'll see when you get there!' Africans don't ask these sorts of questions, he tells me. They wait to experience it for themselves. I find this lesson is congruent in our balafon lessons. Therein opens a question: how does a culture propagate and discourage certain kinds of thinking/questioning/learning? And how does it affect me-or any practitioner-when our natural proclivities are discouraged? Other Africanist scholars such as Paul Stoller and Abu-Lughod have noted such similarities in doing fieldwork. Where, when asking questions out of context one receives careless or fabricated answers (Stoller and Olkes 1987, Abu-Lughod 1986). For me, it has been a longterm learning process to trust and focus on the living experience, to feel it in my body instead of verbalize about it. My meditation practice reinforces Abou's lesson, putting the emphasis back on the moment-to-moment experience, Having discussed these experiences with Stoller and other scholars who interact with Africa, we are most certainly transformed by these experiences when we return home. In the classroom, students reflect on the psychological and emotional aspects of assimilating to another's way of meeting the world. We might ask, is it uncomfortable? What emotional need is not being met? Is it met in another way? Is it acceptable to, for example, not know in advance? What are the advantages and disadvantages to both ways of being in the world?

\section{Embodying Representation}

Embodying representation is the non-written part of the final ethnography. Students may use photography, film, creative writing, performance, and other creative media to improve the sensorial quality of representing the experience. Performances may include native collaborators. In the defense of my dissertation in 2017, playing the balafon for my committee was an inevitable part of my process. Not only did it exhibit what I learned, but it became an invaluable tool to describe certain phenomena that would be laborious to explain with just words.

In Belgrade, our month-long fieldschool ended with an exhibition in an art venue, open to the public, called "Sketching Belgrade: an ethnographic instillment." Students created a multimedia exposition to represent vignettes of their impressions of Serbian culture. There were photography exhibits, recreations of Belgrade graffiti, Kafana tables with red and white, checkered tablecloths, plates of half-eaten Serbian food, and bottles of Rakja for tasting. There were two listening stations for students who composed sound installments. There were three separate videos displayed on blank walls. Visitors, Belgradian host family members and friends, walked around the exhibit and reflected on how Canadians experience Belgradian life. In retrospect, we could improve on this exhibition and made it more interactive and educational. For example, we can incorporate live skits that also demonstrate students' transitions from home to host ways of being. We might invite local teachers to participate, to open ourselves up for critique by our hosts. Furthermore, a fieldschool might focus on a certain kind of representation, such as film, or acting, or fine arts. There are many possibilities to explore.

\section{Conclusion: Transforming ourselves}

In the process of embodying another culture, we are literally transforming our own bodies and minds into new ways of experiencing and expressing life. This is an emotional, psychological, as well as intellectual endeavor, and TE intends to create space to explore these multidimensional facets of cross-cultural human interactions. The fieldwork process from sensorial observation to the embodied representations intends to open a space for emotional involvement with the material. As Behar eloquently said of the oxymoron that is participantobservation, "get the 'native point of view,' pero por favor without actually going native" (Behar 1997: 5). As crosscultural learners we necessarily get emotionally involved, and this is the goal to deeply understanding from another perspective. TE offers a method of doing this intelligently, with self-reflexivity, compassion for self and others, integrity, and vigor.

Insisting on an embodied representation of a foreign culture is intentionally contrary to the emphasis on strictly academic writing in our field. However, artistic forms of representation are growing, as exhibited by the visual anthropologists such as Harvard University's Sensory Ethnography Lab, the AAAs exhibit called Ethnographic Terminalia, and York University's Centre for Imaginative Ethnography in Toronto. If knowing-through-the body is essential for true understanding and empathy, as I suggest, then surely mere academic writing in our representations will limit what we can convey to others. Using art-based training and other creative approaches to inform how we practice anthropology may be rare but I believe that this select group of anthropologists are growing in recognition. Creativity in arts-based methods and mindfulness are tools to strengthen our relatively conservative discipline. By teaching students Transformative Ethnography, by playing with creative techniques, by learning culture through the arts, and by sensing and embodying culture, we can move toward crossing difficult cultural divides, to learn to live and commune with people that may be very different than ourselves while increasing our own sense of humanity, our compassion, for the myriad ways that cultures manifest. Socio- 
cultural anthropologists emerging in embodying and sensorial ethnographic practices have learned how to transform gracefully, back and forth across cultural divides. This article is a proposal to capitalize on such a talent, not financially, but for the benefit of cross-cultural understanding in our ever-increasing globalized planet. This article is my contribution toward that end. Those of us who engage and excel in cross-cultural acrobatics must share our wisdom and use our skills and to teach others the art of crossing cultures mindfully, responsibly, and critically. 


\section{References}

Bateson, Gregory. (1972), Steps to an Ecology of the Mind. New York: Random House. (1979), Mind and Nature: a necessary unit. New York: Dutton.

Behar, Ruth. (1997), The Vulnerable Observer: anthropology that breaks your heart. Boston: Beacon Press.

Benedict, Ruth. (1934), Patterns of Culture. New York: Houghton Mifflin Harcourt.

Blacking, John. (1977), The Anthropology of the Body. New York: Academic Press. (1974), How Musical is Man? Seattle: University of Washington Press.

Bourdieu, Pierre. (1990), The Logic of Practice. Stanford: Stanford University Press.

Casting-Taylor, Lucien. Sensory Ethnography Lab. Retrieved on September 12, 2017 at https://sel.fas.harvard.edu/

Charry, Eric. (2000), Mande Music. Chicago: University of Chicago Press.

Chernoff, John Miller. (1979), African Rhythm and African Sensibility. Chicago: University of Chicago Press.

Clifford, James and George Marcus. (1986), Writing Culture: the poetics and politics of writing culture. Berkeley: university of California Press.

Csordas, Thomas. (1990), "Embodiment as a paradigm for anthropology" Ethos 18: 5-47.

Downey, Greg. (2010), "Practice without theory: a neuroanthropolgical perspective on embodied learning" The Journal of the Royal Anthropological Institute.16 (1), pp. 22-40.

Press.

Dreyfus, Hubert L., and Stuart E. Dreyfus. (1986), Mind over Machine. New York: Free Press.

Dumit, Joseph. (2017). Draft of "Don't know where you are going: embodying improvisation in dance, theater, neuroscience and anthropology" to be published in Between Matters and Method: encounters between anthropology and art. Eds. Gretchen Bakke and Marina Peterson. London: Bloomsbury

Duncan, Doug and Pawasarat, Catherine. (2017) The Six Yogas of Naropa meditation retreat at Clear Sky Center, B.C., December 2017.

Elliott, Denielle and Culhane, Sara. (2017), A Different Kind of Ethnography: Imaginative Practices and Creative Methodologies. University of Toronto Press.

Feder, Lisa. (2007), “Learning Culture through a Musical Practice with Manding Jalis in New York" Ph.D dissertation Cornell University.

Feder Lisa and Marko Zivkovic (2015), "Improvisational Presentation on the Fieldschool for Ethnographic Sensibility" presented at the Society for the Social Study of Science, and the American Anthropological Association panel Creative Disorientation: Ethnographic Sensibility as Improvisational Art, November 2015, Denver.

Farkash, Craig. Letter of Support for Lisa Feder, December 24, 2015.

Feld, Stephen, and Keil, Christopher. (1994), Music Grooves. Chicago: University of Chicago Press. 
Geertz, Clifford. (1998), “Deep Hanging Out.” New York Review of Books. 45(16), pp. 69-72.

Gell, Alfred. (1992), "The Technology of Enchantment and the Enchantment of Technology.” Anthropology, Art and Aesthetics. Eds. Jeremy Coote and Anthony Shelton. Oxford: Clarendon Press.

Goffman, Erving. (1967), Interaction Ritual: essays in face to face behavior. New York: Anchor Books.

Grasseni Cristina. (2004), "Skilled Visions: an apprenticeship in breeding aesthetics" in Social Antbropology 12 (1), pp. 41-55.

Hall Edward. (1966), The Hidden Dimension. New York: Anchor Books.

(1983), The Dance of Life. New York: Anchor Books.

Hahn T. (2007), Sensational Knowledge: embodying culture through Japanese dance. Middletown, Ct: Wesleyan University Press.

Hanh, Thich Nhat. (2016), The Miracle of Mindfulness. Beacon Press.

Hanks, William F. (1996), Language and Communicative Practices. Boulder: Westview Press.

Hissa V. and M. Nogueira. (2013), “Cidade Corpo” in Revisão da Universidade Federal Minas Gerais, 20 (1), pp. 54-77.

Howes, David. (2003), Sensing Culture: engaging the senses in culture and social theory Ann Arbor: University of Michigan Press.

Howes, David and Classen, Constance. (2014), Ways of Sensing: understanding the senses in society. New York: Routledge.

Iyer, Vijay. (2002), "Embodied Mind, Situated Cognition, and Expressive Microtiming in African-American Music.” Music Perception 19: 387-414.

Jain, Lochlann. (2015), Funding application for Empathy Lab Graduate Student Training.

Joas, Hans. (1996), The Creativity of Action, Chicago: University of Chicago Press

Ladzekpo, C.K. "The Myth of Cross-Rhythms" in Foundation Course in African Dance-Drumming Retrieved on October 15, 2016 from: www.ladzekpo.com

Lee J. and Ingold T. (2006), "Fieldwork on Foot: perceiving, routing, socializing" in S. Colman and C. Collins (eds) Locating the Field: space, place and context in Anthropology. Oxford: Berg, pp 67-86.

Low, Setha. (2017), Spacializing Culture: the ethnography of space and place. New York: Routledge.

Lund, K. (2008), "Seeing in motion and the touching eye: walking over Scotland's mountains, in R. Bendix and D. Brenneis guest editors 'The Senses' Etnofoor: Anthropological Journal. 18 (1), pp. 27-42.

MacDougall, D. (1998), Transcultural Cinema Princeton, NJ: Princeton University Press.

McIlwraith, Thomas. (2016), “The Disorienting Dilemma in teaching introductory anthropology” Teaching Anthropology 6(1), pp. 57-65.

Mezirow, Jack. (1991) Transformative Dimensions of Adult Learning. San Francisco: Jossey-Bass.

Myers, Natasha and Joseph Dumit, (2011) "Haptics: Haptic Creativity and the mid-embodiments of experimental life" A Companion to the Anthropology of the Body and Embodiment, first edition. Edited by Frances E. Mascia-Lees. Blackwell Publishing Ltd. 
Pelias, Ronald J. (2007), "Performance Ethnography" Blackwell Encyclopedia of Sociology. Edited by George Ritzer.

Pink, Sarah. (2008), "Mobilizing Visual Ethnography: making routes, making place making images." Forum: Qualitative Social Research 9(3).

(2015) Doing Sensory Ethnography: 2nd Edition. Sage: London.

Rinpoche, Yongey Mingyur. (2007), The Joy of Living. New York: Harmony Books.

Schneider, Arnd and Christopher Wright. (2013), Anthropology and Art Practice Bloomsbury Academy.

Schön, Donald. (1987), Educating the Reflective Practitioner. San Francisco: Jossey-Bass.

Schutz, Alfred. (1951), "Making Music Together: A Study in Social Relationship", Social Research 18 (1), pp. 76-97, reprinted in Symbolic Anthropology, ed., Janet Dolgin, David.

Small, Chistopher (1998), Musicking: the meanings of performing and listening. Middleton: Wesleyan University Press.

Sousanis, Nick. (2015), Unflattening. Cambridge MA: Harvard University Press.

Stoller, Paul and Olkes, Cheryl. (1987), In Sorcery's Shadow Chicago: University of Chicago Press.

Taussig, Michael. (1993), Mimesis and Alterity: a particular bistory of the senses. Psychology Press.

Turner Victor and Edith Turner. (1982), "Performing Ethnography," The Drama Review 6:2. MIT Press.

Wong, Deborah. (2008), "Moving: From Performance to Performative Ethnography and back again." Shadows in the field: New perspectives for fieldwork in Ethnomusicology pp. 76-89. 